\title{
Multiple scrotal epidermal cysts: A clinical case
}

\section{Cheymae Saadani Hassani, Sara Elloudi, Fatima Zahra Mernissi}

\author{
Department of Dermatology, CHU Hassan II, Fès, Morocoo
}

Corresponding author: Dr. Cheymae Saadani Hassani, E-mail: ch.saadani@gmail.com

A 45 year old male came with multiple painless swellings all over the scrotum (Fig. 1) since last five years. On examination, multiple swellings were found arising from scrotal skin, which were pearly white in color and were firm in the consistency, and the largest was measuring $2,5 \mathrm{~cm}$. Scrotal wall could be moved easily over the testicles. The findings were consistent with a diagnosis of multiple epidermal cysts of scrotum. The patient was advised surgery with complete excision, however he refused surgery.

Epidermal cysts are the most common benign epithelial cysts and are generally devoid of malignant potential. These occur commonly in hair-bearing areas mostly on the scalp, also on the face, neck, back and scrotum [1]. Histologically, cysts are lined by stratified squamous epithelium and contain loosely packed keratin debris and cholesterol. A complete removal of the cyst is the only choice of treatment because no neoplastic malignant lesion or remote metastases were reported in the literature contrary to the proper skin's cysts which can be malignant [2].

In conclusion, multiple epidermal cysts over the scrotum is a rare condition, and men use to ignore the lesions, as the condition is painless, but should be promptly treated if infected to avoid fatal sequels such as Fournier's gangrene.

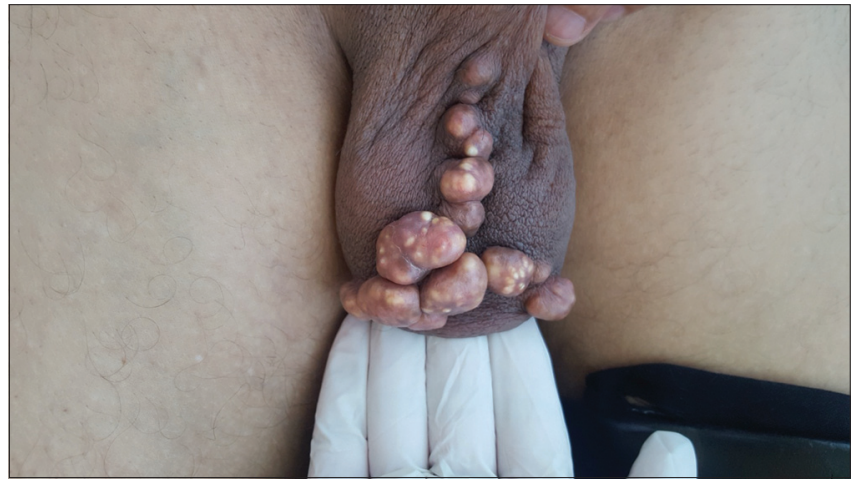

Figure 1: Multiple epidermal cysts of scrotum.

\section{Consent}

The examination of the patient was conducted according to the Declaration of Helsinki principles.

\section{REFERENCES}

1. Prasad KK, Manjunath RD. Multiple epidermal cysts of scrotum. Indian J Med Res. 2014;140:318.

2. Zabbowski T, Wajszczuk M. Epidermoid cyst of the scrotum: A clinical case. Urol J. 2014;11:1706-9.

Copyright by Cheymae Saadani Hassani, et al. This is an open-access article distributed under the terms of the Creative Commons Attribution License, which permits unrestricted use, distribution, and reproduction in any medium, provided the original author and source are credited. Source of Support: Nil, Conflict of Interest: None declared. 